\title{
CHEMICAL WARFARE AGENTS PERMEATION THROUGH LAYERED ADSORPTION MATERIALS
}

\author{
Pavel OTŘÍSAL*, Jiří SLABOTINSKÝ**, Jakub VANĚK**, Stanislav FLORUS* \\ *Nuclear, Biological and Chemical Defence Institute of the \\ University of Defence in Brno, Vyškov, Czech Republic \\ **National Institute for Nuclear, Chemical and Biological Protection, \\ Kamenná, Milín, Czech Republic \\ pavel.otrisal@unob.cz, slabotinsky@sujchbo.cz, vanek@sujchbo.cz, \\ stanislav.florus@unob.cz
}

\begin{abstract}
The adsorption of permeating chemical compounds on the textile materials active surface is one of many principles of personal protection against dangerous chemical compounds including chemical warfare agents. The adsorption principle is generally known. However, its effective application especially in connection with the enhancing protection efficacy follows certain significant rules. A development of new textile materials based on the application of adsorbents in the combination with nanofibrous materials is the main topic of contemporary research in this area. This contribution sums up the theoretical basis of adsorption-based protective efficacy and also brings new experimental results of sorption and permeation of live CWA agents and their simulants through different samples of layered composite materials. Results are related to the basic structural parameters of nanotextiles and applied adsorbents.
\end{abstract}

\section{Keywords: permeation, chemical warfare agents, nanotextile, adsorbents}

\section{Introduction}

Permeation, or penetration, is principally common to all chemicals, including chemical warfare agents (CWA). The difference is, however, which material deposits resistance to this permeation. If the material is compact, thus non-porous (sometimes called impermeable) forms, the permeation process is dependent only on the diffusion with which the penetrating molecules literally penetrate the structure of the material according to their freedom. In polymeric materials, so-called vacuums (cavities) are created by the random movement of polymer chains or their looser particles. Otherwise, different case is within porous materials where the structure flows freely. Its intensity depends on the size and density of the pores, as well as their length and curvature. If such active particles (absorbing, adsorbing or even chemically decomposing) are incorporated into the structure of the material, they literally "suck" the penetrating substance from the free flow, with diffusion, usually surface, also playing a significant role here.

In both cases of permeation, however, the driving force is the concentration gradient between two spaces separating the material. Thus, the separating material within the meaning of this article is a protective layer of a given thickness forthe production of an anti-gas protection garment. These are, in particular, porous materials of textile character with embedded nanoparticles of the adsorbent, respectively catalyst. 
Experimental results with CWA and their more accessible simulants follow the theoretical knowledge of the capture and penetration process of these substances, especially the characteristic data affecting the behavior of the whole system. The work focuses primarily on the influence of socalled structural parameters of the layered system, including sorption surface size, porosity and size and also distribution of individual pore types as well as influence of

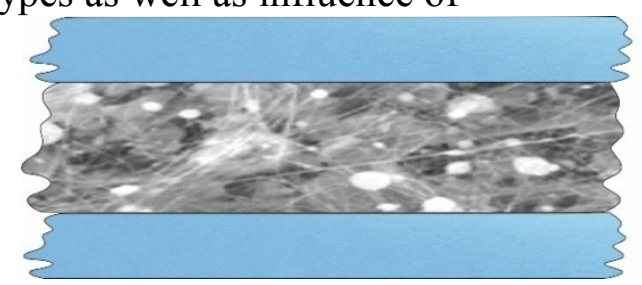

Figure 1: The scheme of the nanocomposite layer. Larger white spots are adsorbent particles, white mesh are nanofibres and dark places are empty space (gap)

This system is exposed to a chemical compound (test chemical) concentration that penetrates through the concentration gradient (between external $C_{0}$ on the face side and $C_{h}$ on the underside) by diffusion and eventually due to convective flow at the forward velocity $v$. In the nanocomposite layer, the adsorbent is captured, thereby reducing the initial concentration ofthe penetrant $C_{0}$ in the space not filled by the

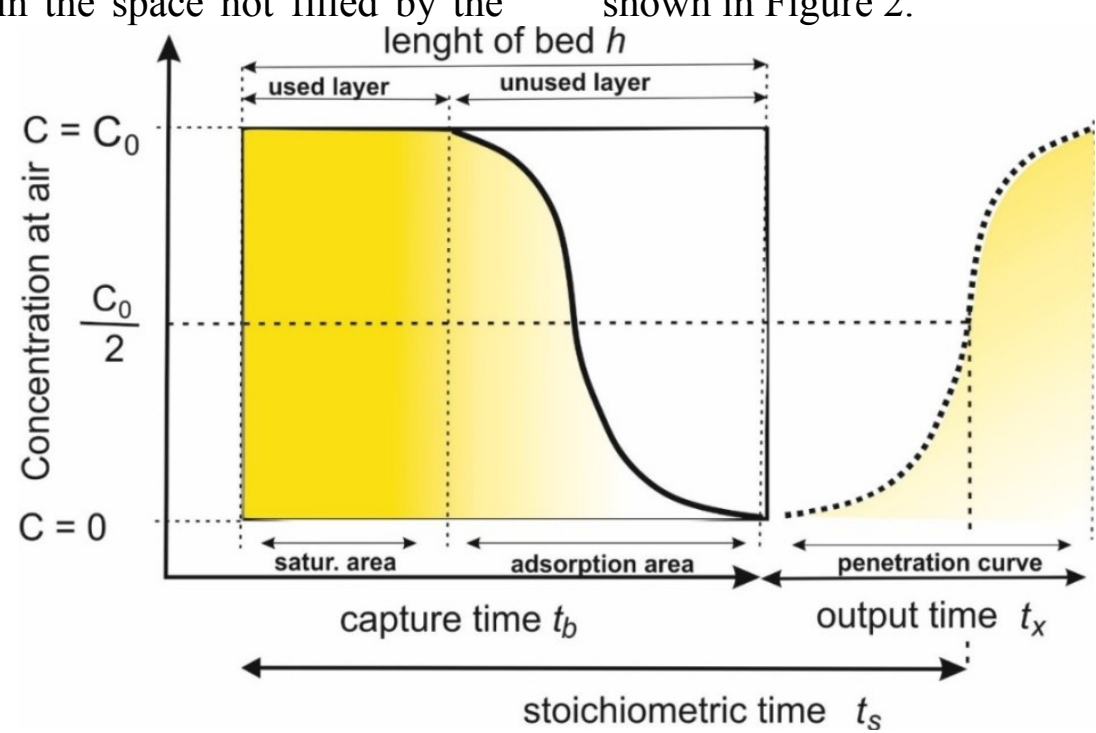

Figure 2: The scheme of a change of permeation concentration in the adsorption layer and recording the concentration wave at the exit of the layer. The stoichiometric time is related to the transfer zone symmetry for total capture corresponding to the $C_{0} / 2$ concentration

The permeation curve is the mirror image of the mass transfer zone moving through sorbent to the $C_{x}$ concentration, with $x$ being the distance from the nanocomposite face. The thickness of the entire layer is then $x=h$. Permeation through the layer can be monitored by temporal change of concentration on the underside of the membrane, thus at the site $x=h$. Its image is the so-called breakthrough curve of the change of concentration on the time as shown in Figure 2.

\section{Chemical compounds vapors
permeation through composite layered system} The term of ,composite system" is used composed of a network of nanofibres filled with a suitable adsorbent and attached to a nonwoven web.

\section{spunbond \\ nanocomposite \\ spunbond}

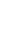


$[1,2]$.Ideally, as shown by Jonas-Wheeler's equation, the mass transfer curve is symmetrical with respect to stoichiometric time.This equation, converted to a more general shape related to the different positions in the layer has the shape: [3]

$t=\frac{\rho_{b} q_{0}}{c_{0}}\left[\frac{x}{v}-\frac{1}{k_{v}} \ln \left(\frac{c_{0}-c_{x}}{c_{x}}\right)\right]$

Where:

$t$ - permeation time through the layer; $\rho_{\mathrm{b}^{-}}$ bulk density of the bed; $q_{0}$ - equilibrium adsorption capacity at $c_{0} ; c_{0}$ - adsorbate concentration in the inlet air, thus at $x=0 ; x$ axis distance in the bed; $\mathrm{v}$ - gas velocity through the surface (face); $k_{v^{-}}$total coefficient of adsorption velocity $\left(\mathrm{s}^{-1}\right)$ (including the coefficient of mass transfer $k_{a}$ in a thin film on the surface of the particle even in the particle $k_{0}$, including deviations from the constant flow, $c_{0}$ - the concentration of the adsorbate in the inlet air, thus at $x=0, c_{x}$ - the penetration concentration, thus at $x$ ).

It is evident from this that the time flow of the concentration wave (zone) through the adsorption bed. It is also evident that by increasing the flow rate of the entrapped substance $v$, the value of the mass transfer coefficient $k_{v}$ must be increased in order to maintain the protection period $t_{b}$.Or the thickness of the layer must be increased. The stoichiometric time $t_{s}$ corresponds to the situation where the bed concentration equals to half of the input concentration, thus to the sum of the time of the fully utilized layer and the time when the adsorption (thus the fully unused layers) that is formed by the symmetrical shape of the transfer zone takes place. This is in the case when the right member of equation 1 will have zero value. And this happens if $x$ $=h$ is the concentration $c_{h}=c_{0} / 2$.As can be seen from Figures 2 and 3, the within adsorption progresses the concentration interface in the so-called zone, which in the ideal case has a symmetrical shape to the stoichiometric time $t_{s}$.In order for the layer to catch the permeating substance, it must have a minimum length of this zone.

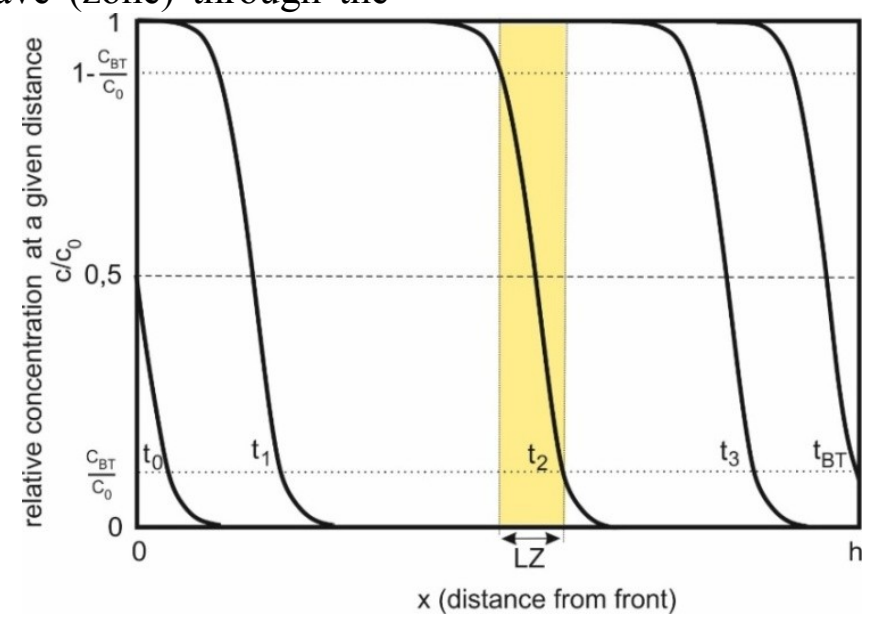

Figure 3: Symmetry of mass transfer zones (relative concentration) by thickness layer $h$ at different distances $x$ corresponding to times $t_{x}$. LZ is the length of the zone, BT is the permeation (breakthrough) time corresponding to the permissible (limit) concentration

The length of the zone as defined in [2] can be determined in two ways, experimentally from the permeation time $t$ or directly from equation 1 , where $t_{x}$ is the permeation time $c$ (respectively $c / c_{0}$ ) and $t_{1}-x$ corresponds to the permeation of the concentration $c_{0}-c$ resp. $\left(1-c / c_{0}\right)$. In the second case, $x=c / c_{0}$; $1-x=1-c / c_{0}$.
$L Z=2 h \frac{t_{1-x}-t_{x}}{t_{1-x}+t_{x}} L Z=2 \frac{v}{k_{v}} \ln \frac{1-x}{x}$

From the second equation it can be seen that the length of the zone will increase by increasing the frontal flow velocity by the layer and by reducing the coefficient of adsorption velocity, and vice versa, with the opposite change of these quantities will decrease. 


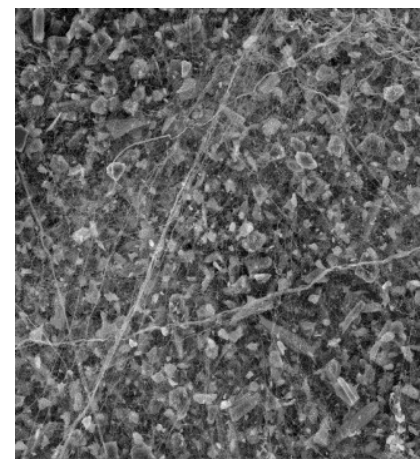

Figure 4: The composite system structure with the adsorbent and nanofibers

These relations operate with quantities irrespective of the porous structure of the composite system, as shown in Figure 1 and in the real form shown in Figure 4. In this case, besides nanofibres and adsorbent particles, there is an empty space that is referred to as a gap, or an empty fraction of the adsorbent bed. This is usually referred to $\varepsilon$ and then it expresses the actual content of the active ingredient (adsorbent) and the given quantity is important for the dynamics of the whole system. It replaces volume density of the bed in equation 1 and at the same time specifies the cumulative magnitude of the quotient of the mass transfer $k_{v}$ for the adsorbent marches where this coefficient is replaced by the coefficient of surface transfer of the mass $k_{a}$ as for example in the derivation of the mass transfer at irreversible adsorption shown in Cussler's [3] publication.

Equation 1 can be linearized to form 3 from which a mass transfer coefficient can be determined. Busmundrud [4] used to evaluate the permeation of dimethylmethylphosphonate and amylacetate with the sorption bed with activated charcoal. By plotting the relative concentration logarithm versus time, the line is linear, as Cussler [3] confirms for the initial low-penetration times.

$\ln \frac{c_{x}}{c_{0}-c_{x}}=\frac{k_{v} \cdot c_{0}}{\rho_{b} \cdot q_{0}} \cdot t-k_{v} \cdot \frac{h}{v}$

If we introduce the velocity of the empty space (gap) $\varepsilon$, then $\rho_{b}$ will correspond to the specific weight of the adsorbent $p_{a d s}$ according to the equation (4): $\rho_{a d s}=\frac{\rho_{b}}{1-\epsilon}$

Rivin and Kendrick [5] modified JonasWheeler's equation as follows:

$t=\left[\frac{q_{0}}{c_{0} \cdot Q}\right] \cdot \frac{\left[M-\rho_{b} \cdot Q \cdot \ln \left(\frac{c_{0}}{c}-1\right)\right]}{k \cdot \tau^{a}}$, where:

$Q$ - volume flow; $M$ - weight of the adsorbent; $\tau$-dimensionless time $\tau=t / \delta$, where $\delta=\epsilon \cdot h / v$ is the residence time in the layer; $\epsilon=$ empty volume of the bed (layer); $h$ - length of the bed; $a-$ an empirical curvature constant that compensates for axial dispersion and corrosion in the bed, $k$ - first order rate constant, where $k \cdot \tau^{a}=k_{v}$, as it is visible for instance from the equation (1). Stoichiometric time $t_{s}$, corresponding $c$ $=c_{0} / 2$ has the value:

$t_{s}=\frac{M \cdot q_{0}}{c_{0} \cdot Q}$

The nanocomposite can also be seen as a permeation layer, similar to a breathable polymeric system respecting Fick's laws. Even here a steady state emerges from which can be determined the so-called effective coefficient of diffusion $D_{\text {eff. }}$ The difference is that in this case the solubility in the polymer is replaced by the adsorption capacity $q_{a d s}$ and the diffusion layer is the result of the convectional flows of the convection mass and perpendicular to it to the adsorption centers. The concentration gradient (or pressure drop) is the driving force of the process in both cases.

\section{Experiemental part}

The measurements were made on samples of carbon-bound composite materials 
entrapped in a polyamide nanofibre mesh laminated on a bicomponent nonwoven fleece of PE/PP (Figure 5). The samples are labeled as $\mathrm{KCB}$, the number after the denomination being the area density of activated charcoal.

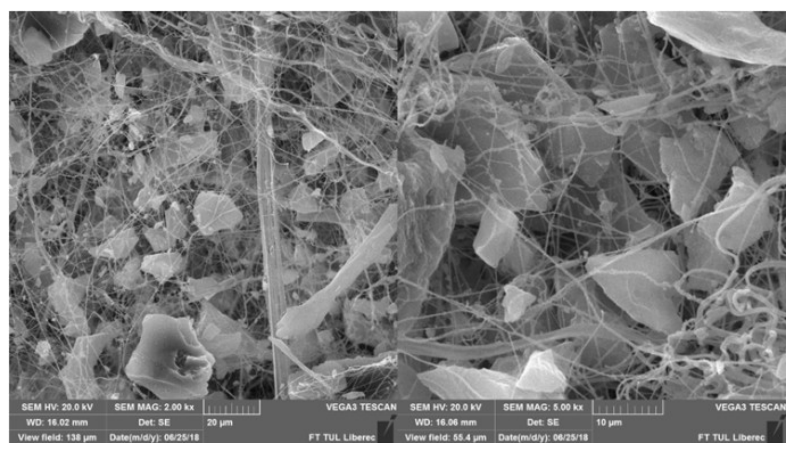

Figure 5: The SEM image of the KCB 12 sample

Table 1 presents the basic characteristics of the used components, expressing their structural parameters which are essential for the vapor permeability of dangerous compounds by adsorption measured at the Center of Nanotechnologies of VSB Technical University of Ostrava (Czech Republic). To determine the specific surface of all samples, the BET (Brunauer,
Emmett, Teller) method was used [6,7]. The distribution of micropores and their size was determined by the Horvath Kawazoe [8] method from the adsorption branch of the isotherms. Distribution and size of mesopores and macropores from the adsorption branch of the isotherms according to de Boer model [9].

Table 1 Structural data of the composite and applied activated charcoal

\begin{tabular}{|l|c|c|c|c|}
\hline Component & $\mathbf{S}\left[\mathbf{m}^{\mathbf{2}} \mathbf{g}^{-\mathbf{1}}\right]$ & $\mathbf{V}_{\text {mono }}\left[\mathbf{c m}^{\mathbf{3}} \mathbf{g}^{-\mathbf{1}}\right]$ & $\mathbf{V}_{\mathbf{M I}}\left[\mathbf{c m}^{\mathbf{3}} \mathbf{g}^{-\mathbf{1}}\right]$ & $\mathbf{V}_{\text {MAME }}\left[\mathbf{c m}^{\mathbf{3}} \mathbf{g}^{-\mathbf{1}}\right]$ \\
\hline KCB 12 & 157.7 & 35.6 & 0.066 & 0.114 \\
\hline KCB 15 & 311.2 & 71.5 & 0.116 & 0.266 \\
\hline KCB 27 & 342 & 78.6 & 0.148 & 0.231 \\
\hline AU & 1141.9 & 262.3 & 0.511 & 0.842 \\
\hline
\end{tabular}

$\mathrm{S}$ - BET specific surface area; $\mathrm{V}_{\text {mono }}$ volume of the adsorbed monolayer; $\mathrm{V}_{\mathrm{MI}}-$ volume of micropores; $\mathrm{V}_{\mathrm{MAME}}-$ total volume of macro and mesopores

The composites were subjected to vapors of test chemicals, the concentration of which was controlled by overlapping of $0.05 \mathrm{~mm}$ thick linear low density polyethylene
(LLDPE) or $0.5 \mathrm{~mm}$ silicone rubber (Q). The principle of measurement with reference to the symbolism of the Jonas Wheeler equation is shown in Figure 6.

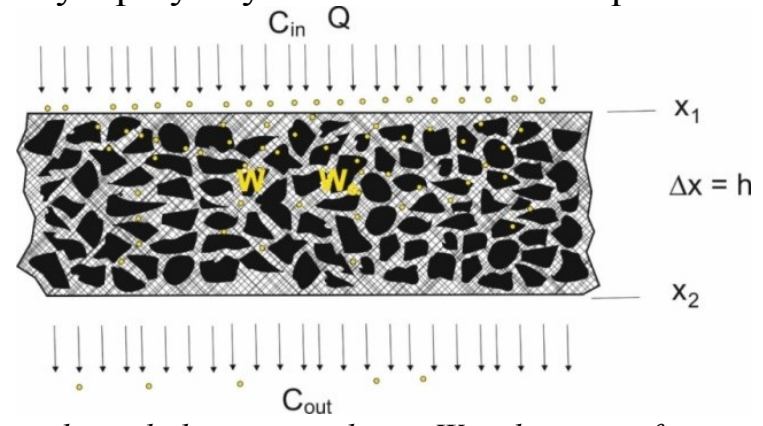

Figure 6: Permeation scheme through the sorption layer. Wis the mass of activated charcoal, W0 is dynamic equilibrium sorption, $Q$ is the volume flow. Yellow points are the molecules of the test substance compared to the size of the charcoal grains 
Due to the lamination of the composite by the LLDPE or Q membrane, the permeation is free of convective flow, thus a purely diffusion process.

The following chemicals were used for testing:

1. CVA:

- sulfur mustard - bis-2(chloroethyl) sulfide (HD);

- soman

Pinacolylmethylphosphonofluoridate (GD);

2. Non-toxicsubstitutes (simulants):

- dimethylmethylphosphonate (DMMP);

- 1,6-dichlorohexane (DCH);

- iodine (I).

\subsection{Methods of determination}

1. Direct indication on the indicator:

- Permeation with iodine gases on the iodine-starch indicatior (JODOTEST) [10];

- HD permeation on chloroamide indicator with congo-red [11];
- GD permeation based on Schönemann'speroxidic reaction [12].

2. Quantitative Method:

- Based on chromatographic detection (CAROUSEL system) [13];

- Based on piezocrystal indication (SORPTEST methodology) [14].

\section{Results}

The core value of the testing which relates to the protective effectiveness of anti-gas garments materials, is the breakthrough time (BT). It expresses the time elapsing between the moment of contact of the test chemical with the surface of the system till the moment of permeation of the admissible amount of this chemical in the form of diffusion flux $\mathrm{F}$ in $\mu$ g.cm-2.min-1 or in the sum of $\mathrm{Q}$ in $\mu \mathrm{g} . \mathrm{cm}-2$. The $\mathrm{F}$ value is determined primarily by the so-called penetration concentration output curves (see Figure 2) measured by detectors (chromatographically or piezoelectrically).

Table 2Values of the HD and GD BT in the layered system determined by the color change of the

\begin{tabular}{|l|c|c|}
\hline \multirow{2}{*}{ Layer system assembly } & \multicolumn{2}{|c|}{$\begin{array}{c}\text { BT } \\
\text { [min] }\end{array}$} \\
\cline { 2 - 3 } & HD & GD \\
\hline $\mathrm{S}$ & 2.7 & 18 \\
\hline $\mathrm{S}+3 \mathrm{xPP}$ & 5.8 & 23 \\
\hline $\mathrm{S}+\mathrm{PP}+\mathrm{KCB} 12+\mathrm{PP}$ & 22.5 & 46 \\
\hline $\mathrm{S}+\mathrm{PP}+\mathrm{KCB} 15+\mathrm{PP}$ & 34 & 48 \\
\hline $\mathrm{S}+\mathrm{PP}+\mathrm{KCB} 27+\mathrm{PP}$ & 44.5 & 53 \\
\hline $\mathrm{S}+\mathrm{PP}+\mathrm{KCB} 27+\mathrm{PP}+\mathrm{KCB} 27+\mathrm{PP}$ & $>180<500$ & 95 \\
\hline $\mathrm{S}+\mathrm{PP}+\mathrm{KCB} 27+\mathrm{PP}+\mathrm{KCB} 27+\mathrm{PP}+\mathrm{KCB} 27+\mathrm{PP}$ & neměřeno & 280 \\
\hline
\end{tabular}

indicator

$\mathrm{S}$ - silicone membrane $0.5 \mathrm{~mm}$; PP - non-woven fleece meltblown; KCB a composite of nanofibres having an activated charcoal content of about $20 \mu \mathrm{m}$ in a nanofibrous polyamide network of about 50 $100 \mathrm{~nm}$, closed between PE/PP bicomponent membrane

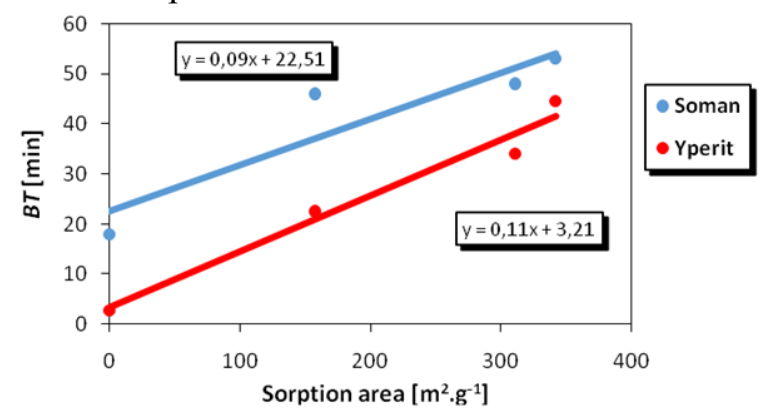

Figure 7: Dependency of the BT on the adsorption area of the incorporated activated charcoal (data see Table 1 and Table 2) 


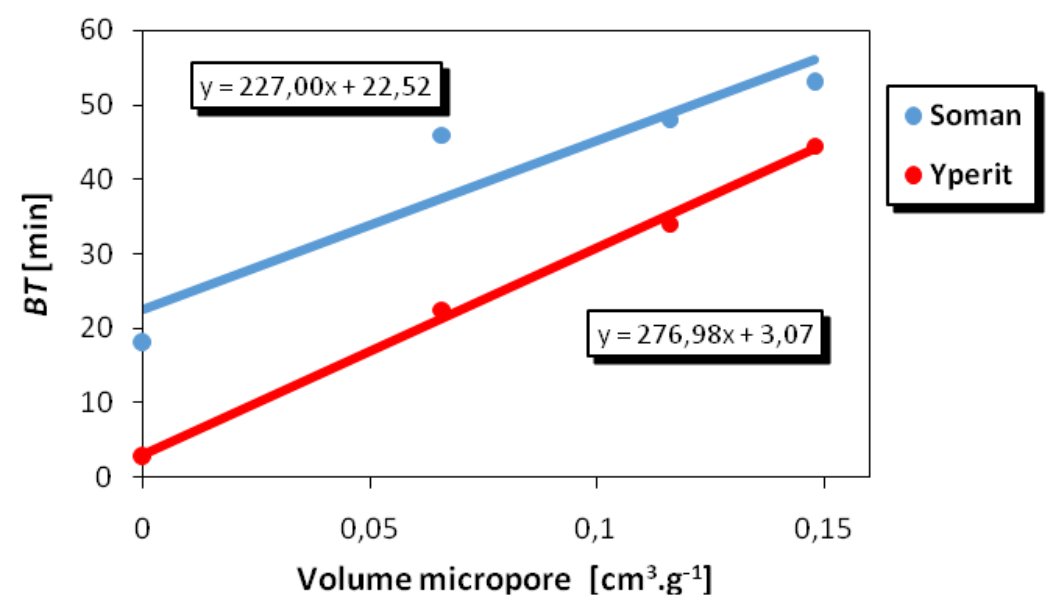

Figure 8: Dependence of the BT on the volume of micropores incorporated in the activated charcoal (see Table 1 and Table 2)

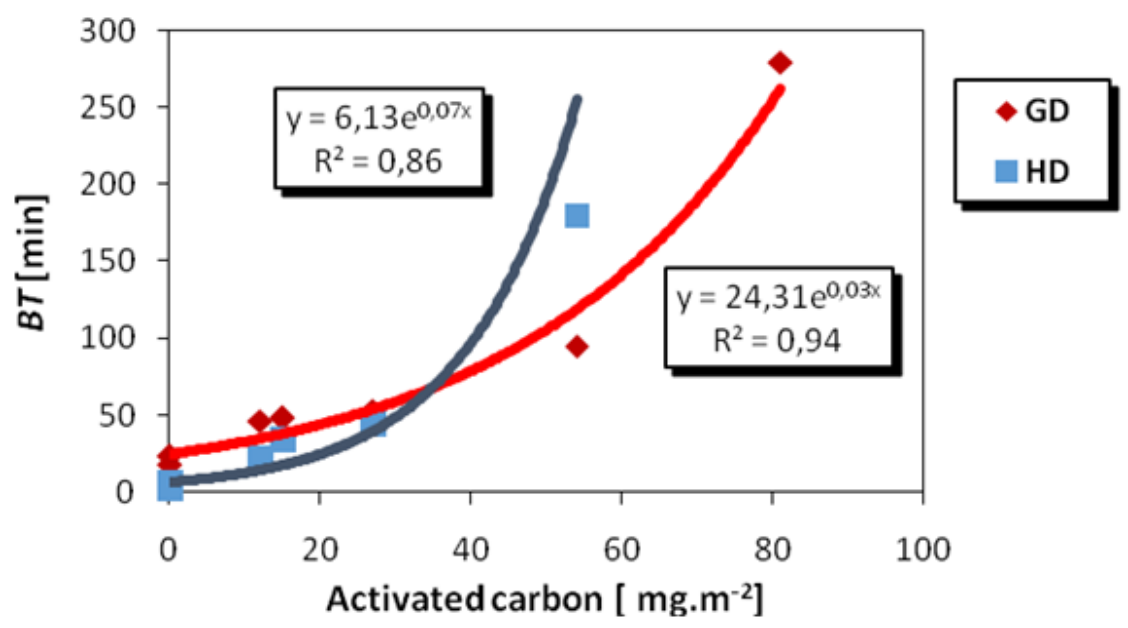

Figure 9: Dependence of the BT on the volume of micropores incorporated in the activated charcoal (see Table 1 and Table 2)

\section{BT of HD measured by Carousel system}

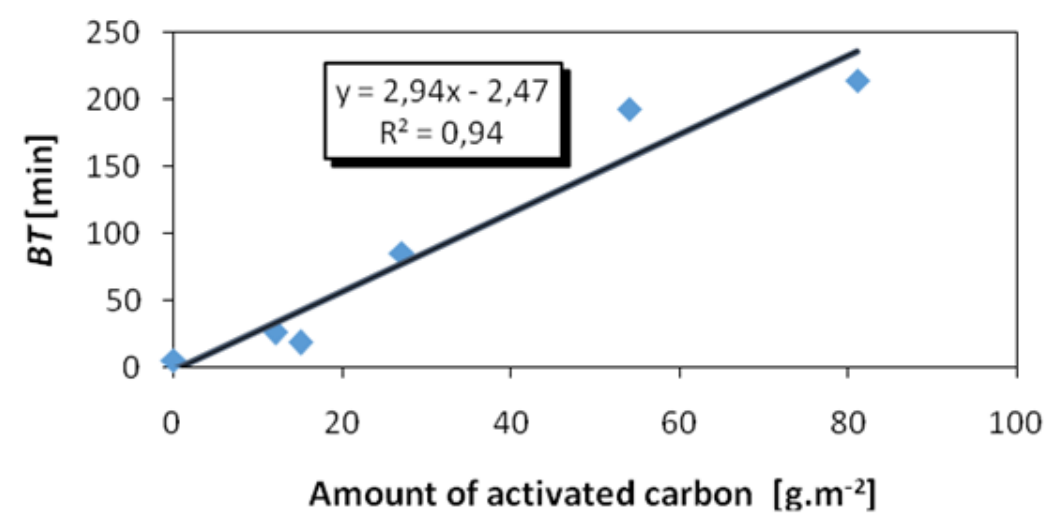

Figure 10: Dependence of the HD BT on the surface density of activated charcoal in the composite and the layered system determined by chromatographic detection for $F=0.1 \mu \mathrm{g} . \mathrm{cm}^{-2} \cdot \mathrm{min}^{-1}$ 


\section{BT of DMMP measured by Carousel system}

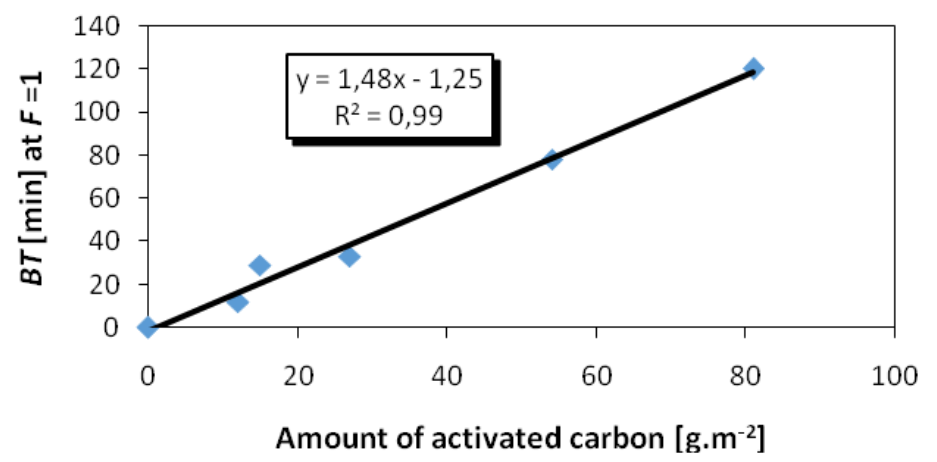

Figure 11: Dependence of the DMMP BT on the composite density of activated charcoal in the composite and the layered system determined by chromatographic detection for $F=1 \mu \mathrm{g} \cdot \mathrm{cm}^{-2} \cdot \mathrm{min}^{-1}$

Table 3Linear dependencies on surface activated charcoal load in the nanotextile

\begin{tabular}{|l|l|l|}
\hline Test chemical & Obtained datae & Equations of linear BT dependence \\
\hline $\mathrm{HD}$ & Indicator & $\mathrm{RD}_{\mathrm{HD}}=3.14 . \mathrm{m}-8.2$ \\
\hline $\mathrm{HD}$ & Carousel system & $\mathrm{RD}_{\mathrm{HD}}=2.94 . \mathrm{m}-2.5$ \\
\hline $\mathrm{GD}$ & Indicator & $\mathrm{RD}_{\mathrm{GD}}=2.8 . \mathrm{m}+4.9$ \\
\hline Iodine vapors & Indicator & $\mathrm{RD}_{\mathrm{I}}=2.65 . \mathrm{m}+6.65$ \\
\hline DMMP & Carousel system & $\mathrm{RD}_{\mathrm{DMMP}}=2.94 . \mathrm{m}-2.47$ \\
\hline
\end{tabular}

\section{Discussion}

From the permeation results, the difference in the BT of both CWA is remarkable in relation to the activated charcoal area density when measured on the chemical indication and the linearity for the HD determined by the so-called concentration curve of the layer (compare Figures 8 and 9).Both methods share only the fact that the protective effect of the composite increases with the density.This is due to the higher proportion of the active sorption surface and the volume of the micropores, as it is evident from Figures 6 and 7.As can be seen from Figure 11, the change in the concentration of the HD in the composite layer is very fast in the initial phase, but asymmetric in the final dynamic equilibrium. This can be attributed to the gradual deposition of HD in several layers of mesopores, as well as in polyamide nanofibers.

Change conc. of HD vs time for $27 \mathrm{~g} \cdot \mathrm{m}^{-2}$

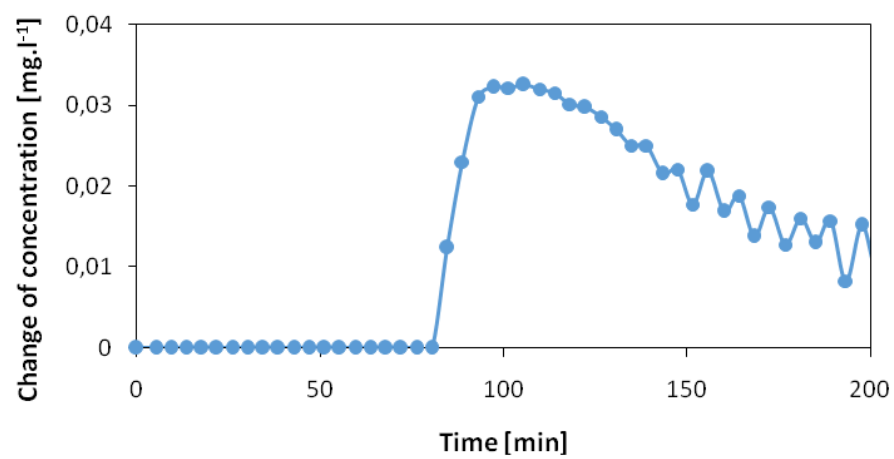

Figure 12: Change of concentration of emerging HD from the AU $27 \mathrm{~g} . \mathrm{m}^{-2}$. The reversion point is the stoichiometric deposition point $t_{s}=100 \mathrm{~min}$ 
If we use in this case equation (2) for the wave length $\mathrm{LZ}$ relative to stoichiometric time, then this is a type of composite with a HD (within the BT of 84 minutes of 9.2.10${ }^{3} \mathrm{~cm}$, thus about half the total thickness of the composite).If we use this value as the velocity form of $\mathrm{LZ}$ for calculation the $k_{\mathrm{v}}$ value, then when obtaining the permeation velocity at the diffusion velocity $\mathrm{v}=0.3$ $\mathrm{cm} \cdot \mathrm{s}^{-1}$, we obtain $k_{\mathrm{v}}=142 \mathrm{~s}^{-1}$, which is comparable with Busmundrud's data for HD permeation through the packed activated charcoal bed [4].

Table 4 Basic data pertaining to the HD and DMMP permeation through the composite layer (math apparatus is not mentioned)

\begin{tabular}{|l|l|l|c|c|c|c|l|}
\hline Sample & $\begin{array}{c}\text { M } \\
{\left[\mathbf{g}^{\left.-\mathbf{m}^{-2}\right]}\right.}\end{array}$ & $\begin{array}{c}\mathbf{S} \\
{\left[\mathbf{c m}^{\mathbf{2}}\right]}\end{array}$ & $\begin{array}{c}\mathbf{h} \\
{[\mathbf{c m}]}\end{array}$ & $\begin{array}{c}\mathbf{V} \\
{\left[\mathbf{c m}^{\mathbf{3}}\right]}\end{array}$ & $\begin{array}{c}\mathbf{V}_{\text {ads }} \\
{\left[\mathbf{c m}^{\mathbf{3}}\right]}\end{array}$ & $\begin{array}{c}\mathbf{B T}_{\mathbf{b}} \\
{[\mathbf{m i n}]}\end{array}$ & $\begin{array}{c}\mathbf{B T} \\
{[\mathbf{m i n}]}\end{array}$ \\
\hline $27 \mathrm{HD}$ & 27 & 4.9 & 0.0197 & 0.0965 & 0.0441 & 5 & $\begin{array}{l}45 \\
(84)\end{array}$ \\
\hline $\begin{array}{l}27 \\
\text { DMMP }\end{array}$ & 27 & 4.9 & 0.0197 & 0.0965 & 0.0441 & 9 & 33 \\
\hline
\end{tabular}

\begin{tabular}{|c|c|c|}
\hline \multirow[t]{2}{*}{ Value } & \multicolumn{2}{|c|}{$\begin{array}{c}M \\
{\left[\mathrm{~g} \cdot \mathrm{m}^{-2}\right]}\end{array}$} \\
\hline & 27 DMMP & $27 \mathrm{HD}$ \\
\hline$S\left[\mathrm{~cm}^{2}\right]$ & 4.9 & 4.9 \\
\hline$h[\mathrm{~cm}]$ & 0.0197 & 0.0197 \\
\hline$V\left[\mathrm{~cm}^{3}\right]$ & 0.0965 & 0.0965 \\
\hline$m_{\text {ads }}[g]$ & 0.0132 & 0.0132 \\
\hline$V_{a d s}\left[\mathrm{~cm}^{3}\right]$ & 0.0441 & 0.0441 \\
\hline$V_{\text {pol }}\left[\mathrm{cm}^{3}\right]$ & 0.00415 & 0.00415 \\
\hline$V_{\text {air }}\left[\mathrm{cm}^{3}\right]$ & 0.0482 & 0.0482 \\
\hline$\epsilon$ & 0.499 & 0.499 \\
\hline $\begin{array}{l}v_{D}\left[\mathrm{~cm}^{-1} \mathrm{~s}^{-1}\right] \\
\text { for } h=0,0373 \\
\mathrm{~cm}, \text { thus with } \\
\text { cover textile }\end{array}$ & 0.0000365 & $\begin{array}{l}0.0000657 \\
\left(7.4 .10^{-6} \text { forBT } 84 \mathrm{~min}\right)\end{array}$ \\
\hline$Q\left[\mathrm{~cm}^{3} \cdot \mathrm{s}^{-1}\right]$ & 0.0001788 & 0.000322 \\
\hline$t_{s}[s]$ & 3420 & 7200 (forBT $84 \mathrm{~min}$ ) \\
\hline$q_{0}\left[\mathrm{~g} \cdot \mathrm{cm}^{-3}\right]$ & 0.0000588 & 0.000101 \\
\hline
\end{tabular}

$\mathrm{V}_{\text {pol }}$ - we consider nanofibre polymer PA6 with density $1.084 \mathrm{~g} . \mathrm{cm}^{3}, \mathrm{~m}=0,0177 \mathrm{~g}\left(\mathrm{vz} 4,9 \mathrm{~cm}^{2}\right), \mathrm{C}_{0}$ DMMP under silicone rubber $\sim 1,27 \mathrm{mg} \cdot \mathrm{l}^{-1}=1,27 \mathrm{ug} \cdot \mathrm{ml}^{-1}, \mathrm{C}_{0}$ HD under silicone rubber $\sim 0,784 \mathrm{mg} \cdot \mathrm{l}^{-1}=$ $7,84 \cdot 10^{-7} \mathrm{~g} \cdot \mathrm{cm}^{-3}$

It is clear from the data in the table that the activated charcoal represents about $50 \%$ of the composite space. Compensation will decrease in proportion to the decrease in weight. Comparison of DMMP is used because of a similar linear dependence of BT on activated charcoal amount. From the point of view of composite membrane construction, namely the required spacing of individual adsorption sites (grains) from each other so that adsorption is the controlling (fastest) step of the entire permeation process, two processes perpendicular to each other can be considered:

- convective flow of chemical compound vapor;

- diffusion flow of the molecules of the chemical compound towards the surface of the grains. 


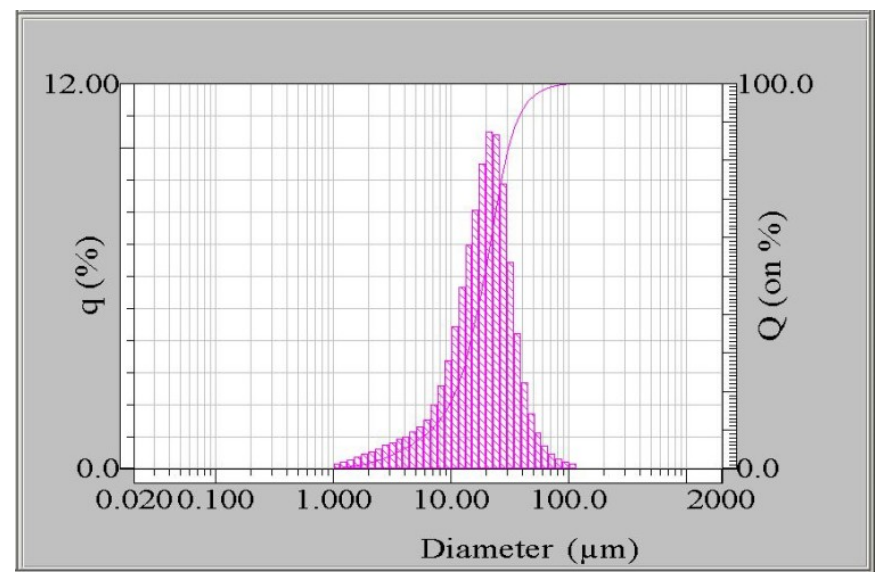

Figure 13: Representation of the Norit adsorbent grain size in the KCB composite system 27

When used the Norit adsorbent, the size of its grains results from the distribution curve in Figure 13. The largest grains are $20 \mu \mathrm{m}$ in size. The calculation of the distance between the grains is based on the assumption that the free space (air) in the composite could be filled with similar particles as the adsorbent and the same number, the diameter of these hypothetical particles being equal to the distance between the solid particles. Of course, an idealized state is assumed where the particles are spherical in shape. However, it is sufficient to clarify the function of the protective mechanism. The calculation, which uses the results in Table 4, shows that the adsorbent grain has an average volume of $4.19 \mathrm{~cm}^{3}$, and a sample of KCB 27 of a diameter of $4.9 \mathrm{~cm}$ and a thickness of $0.0197 \mathrm{~cm}$ (see Table 4) contains approximately $1.05 \times 10^{7}$ individual grains. In order to fill the airspace in the composite sample, the same number of spherical particles (hypothetical) of $21 \mu \mathrm{m}$ diameter is required, which is the same distance as the activated charcoal grain diameter. For an imagination of the diffusion rate, Figure 14 shows the calculated dependence of diffusion velocity in the air on distance. It shows that speed is inversely proportional to the distance, so the closer to the source, the higher it is. In our case, when the results were measured at a vapor diffusion flow rate of $0.0197 \mathrm{~cm}$, the diffusion permeation rate would be about $0.3 \mathrm{~cm} . \mathrm{s}^{-1}$. However, at a distance of $10 \mu \mathrm{m}(0.001 \mathrm{~cm})$ that the HD molecule would have to travel between the grains, this rate is 10 times higher.This means that prior to saturation, the HD will preferably be captured by the adsorbent.

\section{Diffusion rate in air vs. distance}

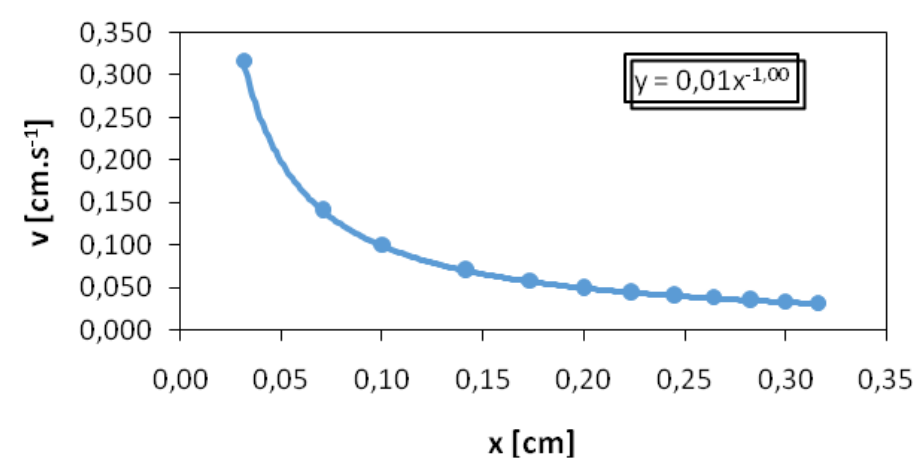

Figure 14: Diffusion rate change with distance from source

\section{Conclusion}

The new, patented technological process developed a composite fabric based on the attachment of activated charcoal microparticles in a polyamide nanofibre mesh and sealed between bicomponent 
nonwoven fabrics. This textile has been tested for capture of CWA and their simulants. The aim was to determine the influence of the area density of the adsorbent on the value of the protective efficiency defined by the so-called breakthrough time or the resistance time against the permeation of these substances through the composite layer. Although the testing was based on known relationships based on the determination of the permeation time of the active charcoal adsorbent layer (Jonas-Wheeler's equation and its modifications), an own evaluation procedure based on the density of coverage and gap and its effect on protective efficacy was developed. In this case, the relationship of the diffusion flux to the particle surface and the convective flow through the spaces between them was applied. From the idealized system came out that if the distance between the individual particles corresponds to a higher flow rate of the chemical molecules flow to them than the convective flow through the layer, the adsorption will lead to the permeation process.

Testing on the KCB 27 composite, with activated charcoal with the areal density of
27 g.m ${ }^{-2}$, showed that even in a very thin layer $(0.0197 \mathrm{~cm})$ almost twice the concentration waves could be achieved. At the same time, the limitation of free space between particles (reduction of gap) leads to the use of a high rate of feed of molecules to the surface. This gap at the average particle size of activated charcoal (about $20 \mu \mathrm{m}$ ) provides information on the possibility of increasing the activated carbon content, if technically possible, up to twice the existing density. That would certainly affect the drape of the fabric. For this, it is certainly preferable to layer the composite, even at the expense of increasing the thickness of the sorption membrane, which increases the BT even though the size of the adsorption area remains about the same in relation to the weight unit (about one third compared to the activated charcoal), but the adsorption capacity and tortuosity for the passage of molecules through the layer are increased. The results at the same time have shown that there is a higher GD capture than HD one and that dimethylmethylphosphonate is a suitable simulant for both types of CWA.

\section{References}

[1] Wood, G. O., Moyer, E. S. A review of the Wheeler equation and comparison of its applications to organic vapor respirator cartridge breakthrough data. Am. Ind. Hyg. Assoc. J., 50, 400-407 (1989).

[2] Lodewyckx, P., Verhoeven, L. Using the modified Wheeler-Jonas equation to describe the adsorption of inorganic molecules: Chlorine. Carbon, 41(6), 1215-1219 (2003).

[3] Cussler, E. L. Diffusion. Mass Transfer in Fluid Systems. Second Edition. Cambridge University, (2005).

[4] Busmundrud, O. Vapor breakthrough in activated carbon beds. Carbon, 31(2), 279-286, (1993).

[5] Rivin, D., Kendrick, C. E. Adsorption properties of vapor protective fabric containing activated carbon. Carbon, 35(9), 1295-1305, (1997).

[6] Lodgewyckx, P. Adsorption of warfare chemical agents. Chapt.10 in Activated Carbon Surfaces in Environmental Remediation. Elsevier Ltd., (2006).

[7] Brunauer, S. Emmet, P.H., Teller, E. J. Amer. Chem. Soc., 60, 309-319 (1938).

[8] Horvath, G., Kawazoe, K. J. Chem. Eng. Jap., 16(6), 470-475 (1983).

[9] Lippens, B. C., Boer, J. H.J. Catal., 4, 319-323 (1965). 
[10] Slabotinský, J. Mazl 11A/95: Determination of the materials resistance against the permeation of iodine. Non-accreditedmethodology. (in Czech).Kamenná: SÚJCHBO, v.v.i., internal methodology, 1995. $12 \mathrm{p}$.

[11] Slabotinský, J. Mazl 03-95/Miktorest: Determination of breakthrough time of protective materials against drops of sulfur mustard in static conditions on the indicator: Mikrotest. (in Czech). Kamenná: SÚJCHBO, v.v.i., internal methodology, 1995. 12 p.

[12] Slabotinský, J. Mazl 36-10/Permeatest 3. Protection of body surface and breathing organs. Determination of protective properties of materials against drops and steams of soman and sulfur mustard: Permeatest 3. (in Czech) Kamenná: SÚJCHBO, v.v.i., internal methodology, 2010. $10 \mathrm{p}$.

[13] Slabotinský, J. Mazl-16/95 - Permeatest 2. Body and respiratory protection. Determination of the resistance of foil materials against the permeation of organic solvents by gas chromatography. (in Czech). Kamenná: SÚJCHBO, v.v.i., internal methodology, 1995. $10 \mathrm{p}$.

[14] Obšel, V., Otřísal, P., Florus. S. Methodology of SORPTEST for quick determination of resistance of porous barrier materials of the adsorptive type and strewn layers of adsorbents against dynamic and static permeation of volatile toxic compounds. (in Czech). [Methodology for a stationary laboratory]. Vyškov: NBC Defence Institute, 2015, p, 96. 